\title{
New accessory palatine canals and foramina in cone-beam computed tomography
}

\author{
H.A.M. Marzook ${ }^{1}$, A.A. Elgendy², F.A. Darweesh ${ }^{3}$ \\ 'Oral and Maxillofacial Surgery Department, Faculty of Dentistry, Mansoura University, Mansoura, Egypt \\ 2Endodontics, Head of Conservative Dentistry Department, Faculty of Dentistry, Zagazig University, Zagazig, Egypt \\ ${ }^{3}$ Oral Biology Department, Faculty of Dentistry, Zagazig University, Zagazig, Egypt
}

Received: 29 May 2020; Accepted: 3 September 2020; Early publication date: 11 September 2020

\begin{abstract}
Background: Palatal surgeries are associated with many complications. Accessory foramina may be a cause of concern. The present study was conducted to assess the presence and to evaluate the anatomical characteristics of accessory palatine foramina (APF) and related bony canals in cone beam computed tomography $(C B C T)$ scans.

Materials and methods: The incidence, location, and types of foramina on the palate were evaluated in 170 CBCT scans. Readings from coronal, sagittal, and axial planes were recorded using a computer programme and evaluated.

Results: Other than nasopalatine, greater and lesser palatine foramina, 278 foramina were seen in the palate in different locations. New APF were found posteriorly in $14.71 \%$ of the studied scans with wide anatomical variations. Unusual foraminal canals were seen crossing the antral floor laterally. The anterior APF were seen in $73.53 \%$ of scans while bilateral APF were found in $43.53 \%$ of cases. Conclusions: Accessory palatine foramina and related canals are frequently seen in CBCT with many anatomical variations. New unusual connecting canals are found passing through the antral floor from palatine foramina to the lateral antral wall. These anatomical structures should be considered in preoperative planning for local analgesia and surgical interventions in the palate. (Folia Morphol 2021; 80, 4: 954-962)
\end{abstract}

Key words: cone-beam computed tomography, anatomical landmarks, new palatine foramina, nasopalatine foramen, palate, canalis sinuosus

\section{INTRODUCTION}

Palatal surgical interventions are associated with different complications. Complications include intraoperative bleeding, wound dehiscence, and nerve injury $[6,8,13,33]$. To avoid these complications, total knowledge of bony neurovascular anatomical variations is recommended $[2,38]$. Cone-beam computed tomography (CBCT) was found to play an important role in studying anatomical variations of the jaws [27]. The palatine foramina and canals were previously studied by many researchers $[21,35]$.

The maxillary nerve is a completely sensory nerve that supplies the maxillary teeth and related soft tissues of the hard and soft palate, nose, upper lip, maxillary sinus, as well as many adjoining structures [37]. The anatomical variations may be a cause of anaesthesia failure or surgical complications. 
Table 1. Distribution of anterior and posterior accessory palatine foramina (APF) in the cone-beam computed tomography scans

\begin{tabular}{lccccc}
\hline No. & Studied structure & No. of readings & No. of patients & Bilateral cases & Per cent \\
\hline 1 & Anterior APF & 234 & 125 & 65 & $73.53 \%$ \\
2 & Posterior APF & 44 & 25 & 9 & $14.71 \%$ \\
\hline
\end{tabular}

Many studies investigated neurovascular structures in the anterior maxilla which may show different variations. Greater palatine canal and nasopalatine canal are among those structures [21, 28, 34-37]. Variants such as accessory canal of canalis sinuosus was studied by many investigators. It could be seen as a unilateral or bilateral canal with a palatal foramen located opposite anterior teeth. Nerves and blood vessels running through these canals often considered as extensions of the infraorbital nerve and its branches. Accessory canals of canalis sinuosus were previously considered a rare anatomical variant but many of these structures were recorded in recent reports $[22,24,26,32,41]$.

In the posterior part of the hard palate, the anatomical features of the greater palatine and lesser palatine canals and foramina were studied [18, 28, $34,36]$. The greater palatine nerve canal is located bilaterally. Its shape, location, and size have been assessed by many research studies $[10,16]$. Reports concerning anatomical variants such as accessory canals in the posterior palatal bone are lacking. CBCT analysis for accessory palatine foramina (APF), however, has not been widely studied or used in clinical dental practice yet. Therefore, it is important to evaluate the anatomical features of APF and related canals in CBCT. This study was undertaken to assess the presence and to evaluate the anatomical characteristics of APF and the related channels using CBCT.

\section{MATERIALS AND METHODS}

The protocol of the present study was approved by the Research Ethics Committee of Mansoura Faculty of Dentistry (code 03100918). Palatal bone was studied in 170 patients (108 female and 62 male) for any additional foramina and canals other than nasopalatine, greater palatine and lesser palatine. Readings from a computer programme (Planmeca Romexis Viewer 5.4.1.R, Planmeca Co., Italy) were recorded by two investigators. CBCT coronal, axial, and sagittal slices from 170 scans were studied to evaluate the occurrence, location, and direction of accessory canals. The recorded foramina were classified according to their location into anterior and posterior accessory palatal foramina. Anterior foramina are those located in front of upper first premolars; however, the others were considered posterior. The mean age of enrolled cases was 35.33 years. Scans with large pathological bony lesions or fractures in the palatal region were excluded. The course and relations of additional canals were studied. Only after studying their related bony canals, APF were considered branched from canalis sinuosus. Agreement between the two investigators is essential for considering recorded foramina. Data were collected for the location, incidence, and course of the anterior and posterior APF and their canals, and evaluated.

\section{RESULTS}

A total of 278 additional foramina of the palate other than nasopalatine, greater palatine, and lesser palatine were seen and recorded from the different planes of 170 CBCT scans. The additional foramina were divided into anterior and posterior accessory palatine foraminal groups (Table 1). Nasopalatine foramen was seen in the midline in all scans with different morphological variations. One hundred and thirty-three (78.24\%) patients showed at least one more additional foramen.

A new type of palatine foramina was detected in the posterior region of the palate in 25 CBCT scans with abnormal directions of their associated bony canals (Fig. 1). These canals were found to extend upward to the medial antral wall and nasal cavity and to follow a lateral course in the floor of the sinus. Posterior accessory palatine foraminal canals were found to exhibit multidirectional course in many cases (Fig. 2). Different positions of posterior APF in the palate were seen (Fig. 3). Multiple posterior additional palatine canal was detected in 12 cases either unilateral or bilateral. Some posterior accessory foramina were found to be passing anteriorly and originating from canalis sinuosus (Fig. 4).

There was a prevalence of the anterior accessory foramina, with significant differences in their positions and anatomical features. Lateral incisor and cuspid region foramina were also seen. In many instances accessory anterior foramina were found to be connected to canalis sinuosus branch of infraorbital 


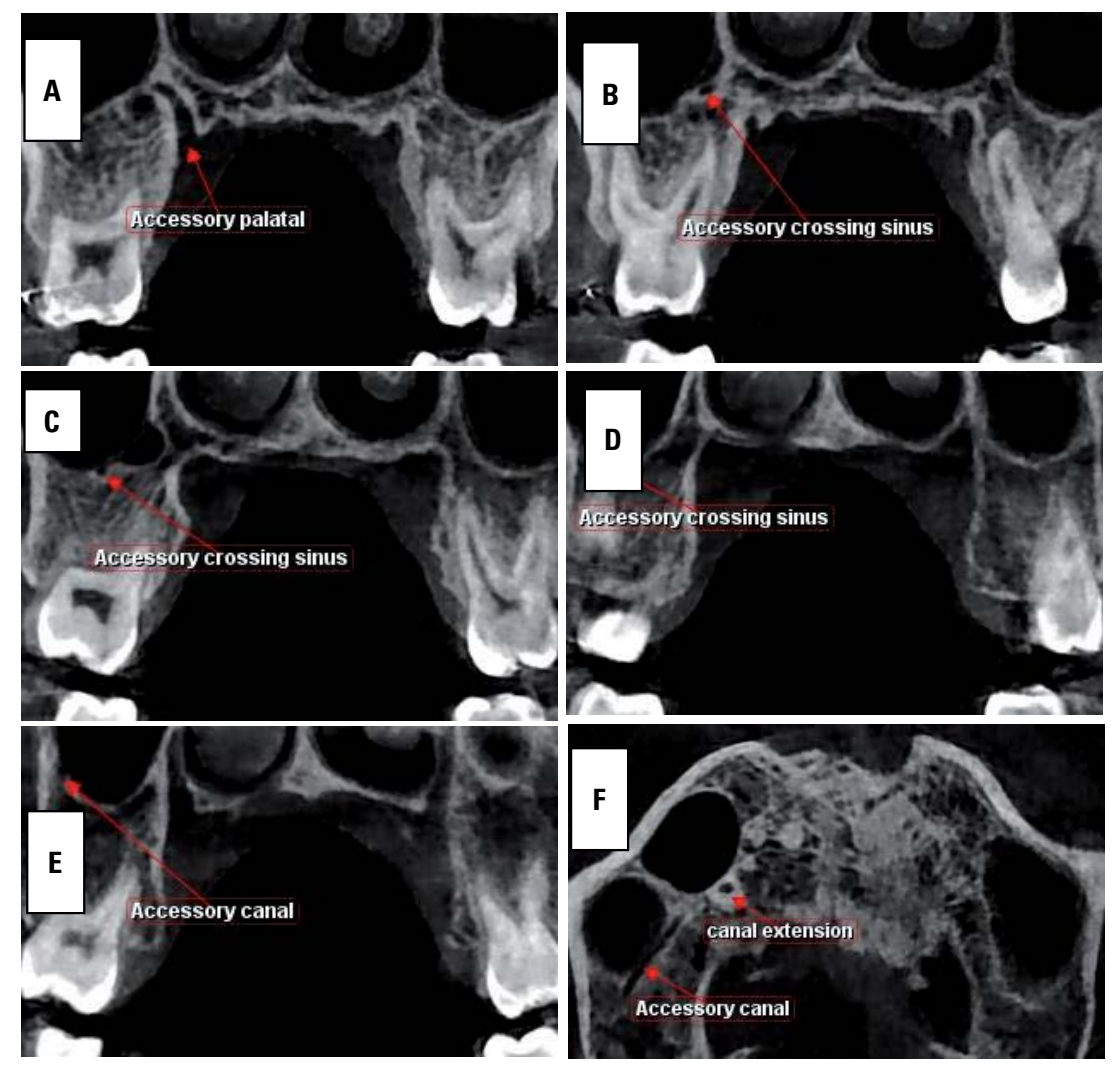

Figure 1. New posterior accessory palatine foramen canal shown in coronal sections passing from palate to maxillary sinus $(\mathbf{A})$; through sinus floor (B), to the middle of the floor (C), then to the lateral antral wall (D), upward posteriorly (E), and in axial section with lateral, posterior, and upward direction $(\mathbf{F})$.

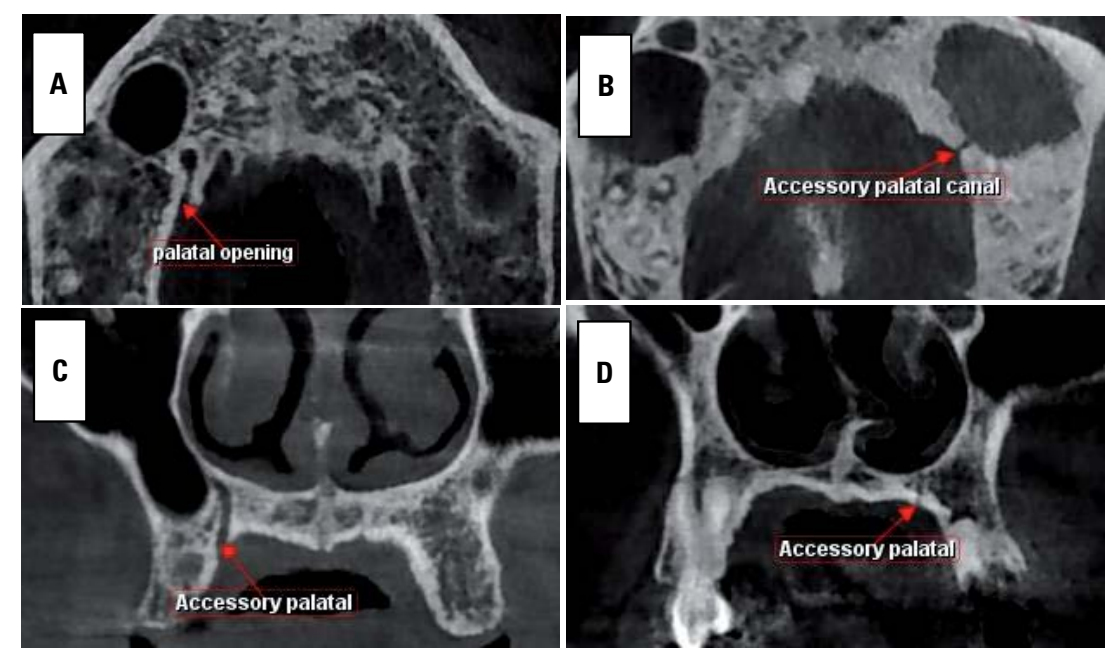

Figure 2. Variants of the new posterior accessory palatine foramina and their canals shown in axial sections directed anteriorly first $(\mathbf{A})$, or passing directly from palate to maxillary, and in coronal sections ascending upward (B), laterally to medial sinus wall (C), or directly through palate to nasal cavity (D).

nerve (Fig. 5) and were directed upward anteriorly. Anterior accessory foramina originating from canalis sinuosus were found to be present in 125 (73.53\%) patients. Different locations of APF in the anterior region were found. Many of the anterior accessory palatine canals were connected to nasopalatine canal and some were found to be related to the supply of upper anterior teeth (Fig. 6). Bilateral occurrence was found in 65 patients. More than two unilateral or bilateral APF could be detected in 88 scans (Fig. 2). 

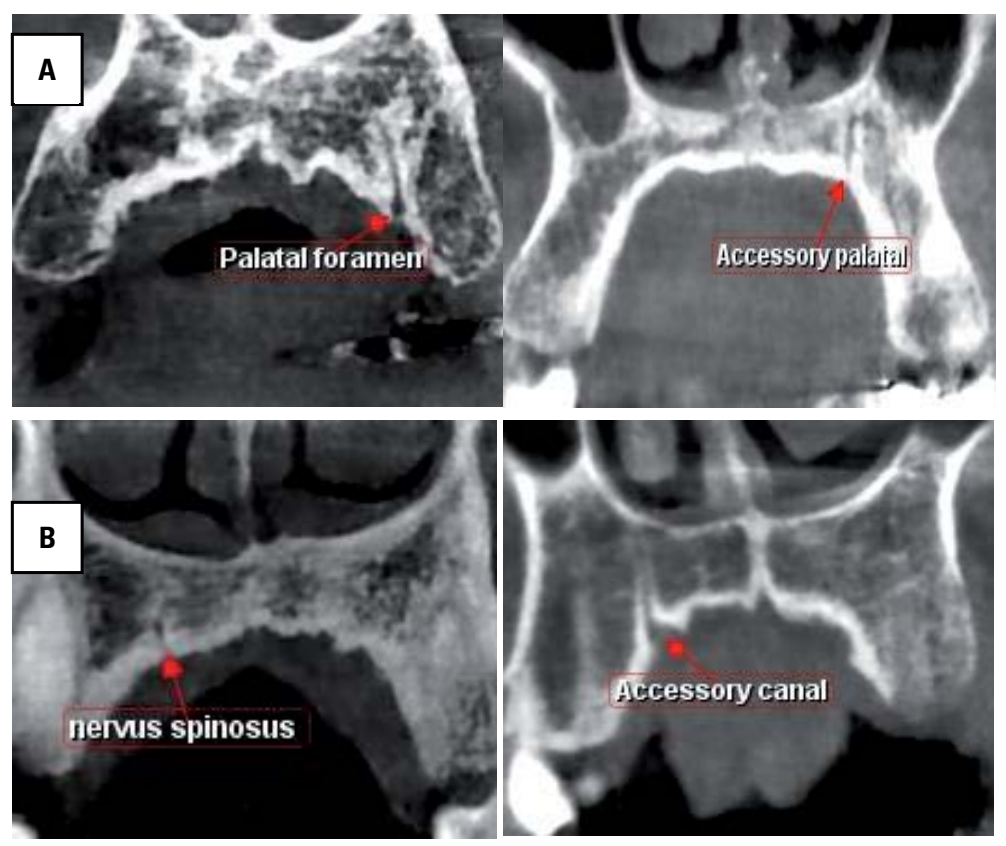

Figure 3. Different positions of posterior accessory palatine foramina in relation to alveolar ridge in coronal sections: A. Near the ridge in most of the cases; B. Away from ridge.
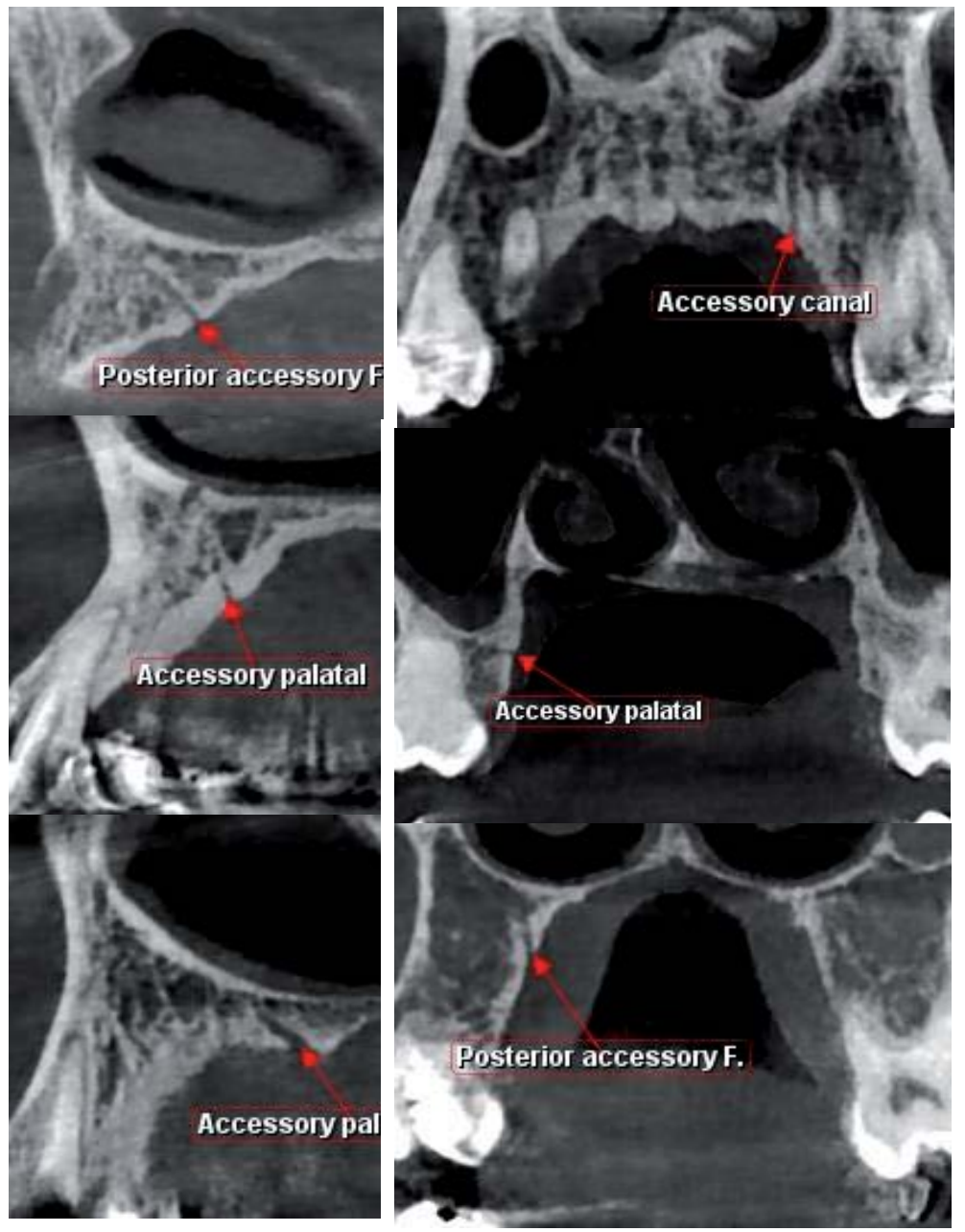

Figure 4. Posterior accessory foramina originating from canalis sinuosus. 


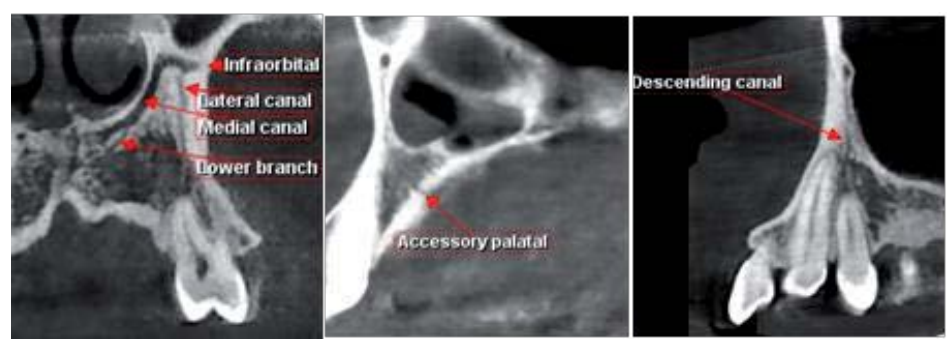

Figure 5. Branching of canalis sinuosus in the upper jaw.
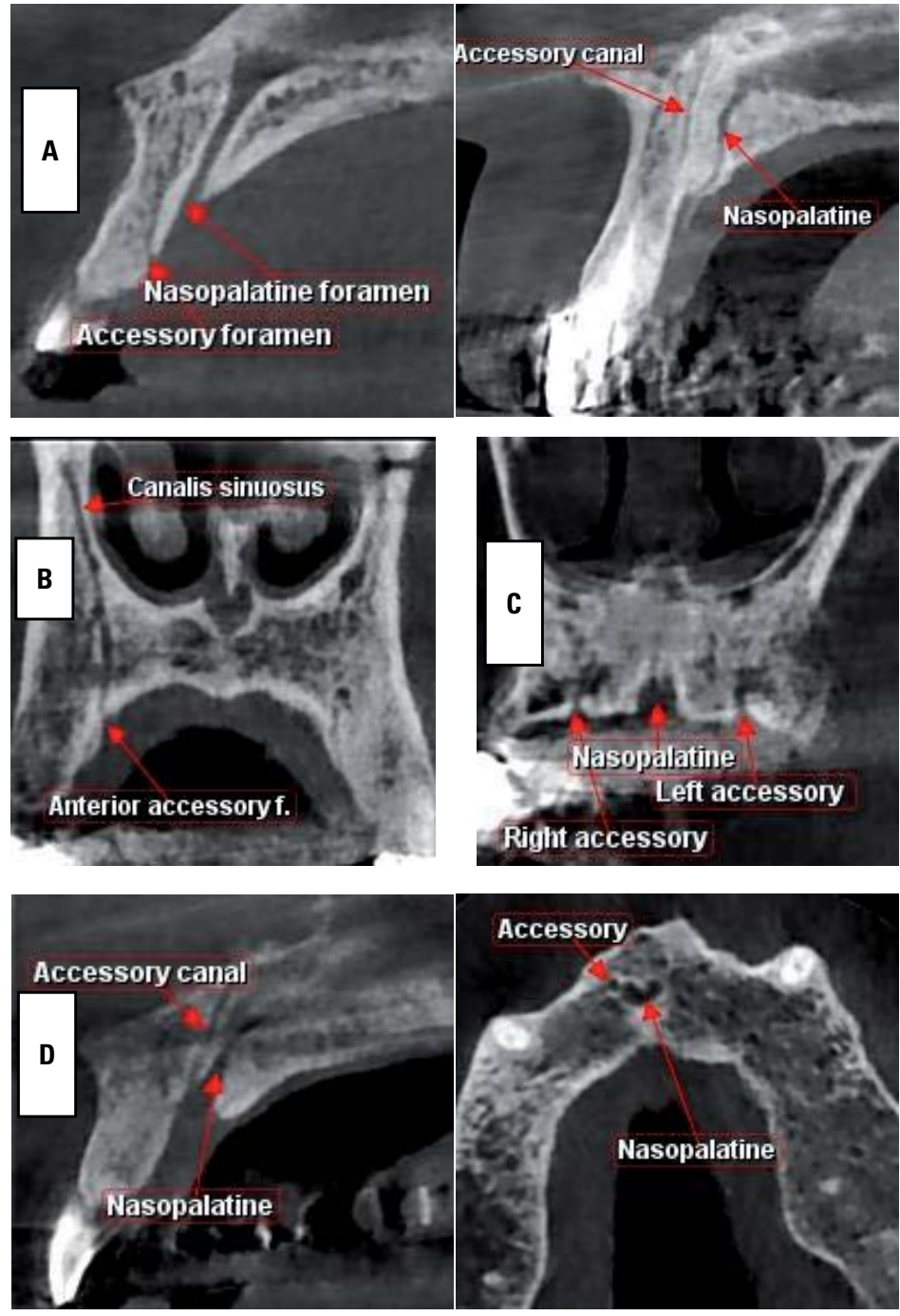

Figure 6. Different relations of accessory anterior palatine canals to nasopalatine canal: A. Anterior; B. Posterior; C. Lateral; D. Opening into nasopalatine foramen.

Additional palatine foramina could not be related to canalis sinuosus in 26 scans (Fig. 3). Variations in size of APF could be seen in many cases (Fig. 4). Additional foramina were found in different coronal (Fig. 5), axial (Fig. 6), and sagittal planes (Fig. 7).

\section{DISCUSSION}

Complications occurring during surgical treatment of palatal conditions had been reported. Identification of the location of neurovascular anatomical structures is essential for the avoidance of complications such as haemorrhage and neurosensory impairment 

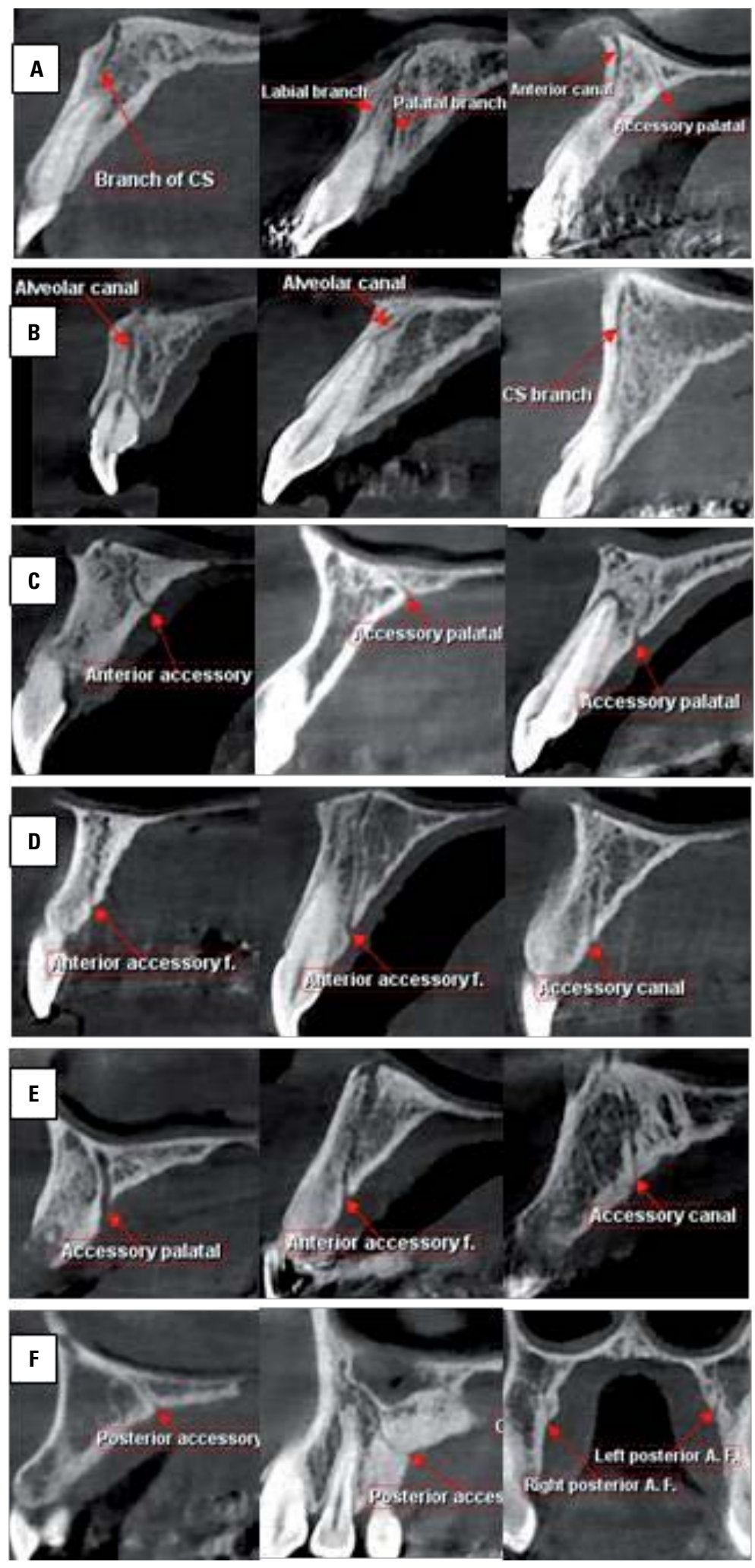

Figure 7. Variation of branching of canalis sinuosus: A. Labial and palatal bony plates branches; B. Dental branches; C. High anterior accessory palatine branches; D. Low anterior accessory palatine; E. Wide or branched; F. Posterior palatine branching unilateral and bilateral. 
$[1,2,6-8,13,33,38]$. Osseous neurovascular structures include the nasopalatine, greater and lesser palatine foramina and their canals $[10,21,31]$. In this study, these structures were found in all cases $(100 \%)$. These findings are in agreement with several previous research results $[9,31]$. There was a high incidence of APF in our adult Egyptian sample. There was a prevalence of the anterior accessory foramina, with many differences in their locations and anatomical features. In most instances, these additional foramina were related to canalis sinuosus. These results are consistent with what had been found in previous studies [11, 17, 39, 40].

More studies are needed to investigate the abnormal lateral origin of the unusual new type of posterior palatine foramina. The possibility of being derived from the posterior superior alveolar nerve may result in a change of the common belief that greater palatine nerve block is sufficient for anaesthesia of palatal gingiva opposing upper posterior teeth. This result may be supported by the findings of previous reports of occurrence of palatal anaesthesia after a single buccal infiltration $[3,5,20]$. On the contrary, it may also put a question mark upon the accuracy of studies investigating the palatal effect of some local anaesthetic solutions proposed to penetrate the alveolar bone after buccal infiltration [23, 25, 29]. Studies searching for the occurrence or the anatomical features of posterior APF and canals are lacking. Failure of greater palatine anaesthesia might be attributed to the presence of this extra abnormal innervation in some patients.

There is no clear evidence in previous studies that multidirectional posterior APF canals are present in humans. Most studies investigated the anatomic features of the greater palatine canal or the opening direction, dimensions, and shape of the greater palatine foramen $[34,36,37]$. Multiple APF were considered previously as double or triple greater or lesser palatine foramina [4, 9]. Our results disagree with these considerations as the lateral extensions of foraminal canals cross the antral floor laterally. This result may also support the recommendations of previous reports concerning the necessity of preoperative planning $[15,19]$.

The findings of the present study proved that there is a connection between many of the anterior accessory palatine canals and nasopalatine canal. Some of these canals were related to the supply of upper anterior teeth. These results are in accordance with some reports indicating this supply $[15,19]$. The presence of anastomosis between different bony canals forming sometimes a plexus or a network of channels in the anterior part of the maxilla may add to the complexity of some periapical surgeries. This may also explain postoperative bleeding or sensory disturbances after endodontic surgery or palatal mucosal grafting in some cases [12].

In our study, cases showed variations of intra-bony canals. Many studies postulated the possibility of the presence of bony nutrient canals and this should be put in consideration [14, 30]. Most recent studies do not clearly demonstrate this.

In this work, there was a high incidence for the APF in comparison to previous studies [26, 32, 38]. A new type of APF was discovered in the posterior region of the palate with abnormal extension of its canal to the floor of maxillary sinus. Any graft or implant placement in this area of the palate should not be done without a thorough CBCT investigation of the area. There was a great variability in the occurrence of palatine foramina and their bony canals anatomy and location in our sample. Considering narrow canals and using recent technology may be the cause of this high occurrence. Thorough preoperative CBCT examination is mandatory to preserve these neurovascular variants in any surgical treatment.

\section{CONCLUSIONS}

Accessory palatine foramina and their related bony canals are present frequently in the palate with high anatomical variability. In the anterior region of the palate, the incidence of anterior accessory foramina was the higher. Posterior APF were also frequently seen with wide morphological variations. These findings should be taken into consideration in preoperative planning for any surgical intervention in the palate to avoid complications. A thorough CBCT examination of the anterior and posterior palatal areas is highly advocated prior to surgery in these regions. In this study, accessory palatine canals were evaluated only on $C B C T$ images, and the contents of the canals were not confirmed. More cadaveric and clinical studies exploring the histological and anatomical contents are essential to validate the current findings.

Conflict of interest: None declared 


\section{REFERENCES}

1. Allareddy V, Vincent SD, Hellstein JW, et al. Incidental findings on cone beam computed tomography images. Int J Dent. 2012; 2012: 871532, doi: 10.1155/2012/871532, indexed in Pubmed: 23304148.

2. Arruda JA, Silva $P$, Silva $L$, et al. Dental implant in the canalis sinuosus: a case report and review of the literature. Case Rep Dent. 2017; 2017: 4810123, doi: 10.1155/2017/4810123, indexed in Pubmed: 28928992.

3. Ashwath B, Subramoniam S, Vijayalakshmi R, et al. Anesthetic efficacy of $4 \%$ articaine and $2 \%$ lignocaine in achieving palatal anesthesia following a single buccal infiltration during periodontal therapy: A randomized double-blind split-mouth study. J Anaesthesiol Clin Pharmacol. 2018; 34(1): 107-110, doi: 10.4103/joacp.JOACP_200_15, indexed in Pubmed: 29643633.

4. Badshah M, Soames R, Khan MJ, et al. Morphology of the human hard palate: a study on dry skulls. Italian J Anat Embryol. 2018; 123(1): 55-63, doi: 10.13128/IJAE-23011.

5. Bataineh $A B, A l-S a b r i$ GA. Extraction of maxillary teeth using articaine without a palatal injection: a comparison between the anterior and posterior regions of the maxilla. J Oral Maxillofac Surg. 2017; 75(1): 87-91, doi: 10.1016/j. joms.2016.06.192, indexed in Pubmed: 27528103.

6. Bouloux GF, Bays RA. Neurosensory recovery after ligation of the descending palatine neurovascular bundle during Le Fort I osteotomy. J Oral Maxillofac Surg. 2000; 58(8): 841-5; discussion 846, doi: 10.1053/joms.2000.8196, indexed in Pubmed: 10935581.

7. Bouloux GF, Perciaccante VJ. Massive hemorrhage during oral and maxillofacial surgery: ligation of the external carotid artery or embolization? J Oral Maxillofac Surg. 2009; 67(7): 1547-1551, doi: 10.1016/j.joms.2009.03.014, indexed in Pubmed: 19531434.

8. Buff LR, Bürklin T, Eickholz P, et al. Does harvesting connective tissue grafts from the palate cause persistent sensory dysfunction? A pilot study. Quintessence Int. 2009; 40(6): 479-489, indexed in Pubmed: 19587889.

9. Cagimni P, Govsa F, Ozer MA, et al. Computerized analysis of the greater palatine foramen to gain the palatine neurovascular bundle during palatal surgery. Surg Radiol Anat. 2017; 39(2): 177-184, doi: 10.1007/s00276-016-1691-0, indexed in Pubmed: 27177906.

10. Chrcanovic BR, Custódio ALN. Anatomical variation in the position of the greater palatine foramen. J Oral Sci. 2010; 52(1): 109-113, doi: 10.2334/josnusd.52.109, indexed in Pubmed: 20339241.

11. de Oliveira-Santos C, Rubira-Bullen IRF, Monteiro SAC, et al. Neurovascular anatomical variations in the anterior palate observed on CBCT images. Clin Oral Implants Res. 2013; 24(9): 1044-1048, doi: 10.1111/j.16000501.2012.02497.x, indexed in Pubmed: 22587228.

12. Dridi SM, Chousterman M, Danan M, et al. Haemorrhagic risk when harvesting palatal connective tissue grafts: a reality? PERIO. 2008; 5: 231-240.

13. Filippi A, Pohl Y, Tekin U. Sensory disorders after separation of the nasopalatine nerve during removal of palatal displaced canines: prospective investigation. $\mathrm{Br} J$ Oral Maxillofac Surg. 1999; 37(2): 134-136, doi: 10.1054/ bjom.1997.0092, indexed in Pubmed: 10371320.
14. Goodman-Topper ED, Chosack A. Radiographic appearance of nutrient canals in the region of the erupting permanent maxillary cuspid. Oral Surg Oral Med Oral Pathol. 1989; 67(5): 606-610, doi: 10.1016/0030-4220(89)902818, indexed in Pubmed: 2717159.

15. Gurler G, Delilbasi C, Ogut EE, et al. Evaluation of the morphology of the canalis sinuosus using cone-beam computed tomography in patients with maxillary impacted canines. Imaging Sci Dent. 2017; 47(2): 69-74, doi: 10.5624/isd.2017.47.2.69, indexed in Pubmed: 28680842.

16. Hafeez NS, Ganapathy S, Sondekoppam R, et al. Anatomical variations of the greater palatine nerve in the greater palatine canal. J Can Dent Assoc. 2015; 81: f14, indexed in Pubmed: 26214834.

17. Hu KS, Kwak HH, Song WC, et al. Branching patterns of the infraorbital nerve and topography within the infraorbital space. J Craniofac Surg. 2006; 17(6): 1111-1115, doi: 10.1097/01.scs.0000236436.97720.5f, indexed in Pubmed: 17119413.

18. Iwanaga J, Kido J, Lipski M, et al. Anatomical study of the palatine aponeurosis: application to posterior palatal seal of the complete maxillary denture. Surg Radiol Anat. 2018; 40(2): 179-183, doi: 10.1007/s00276-017-1911-2, indexed in Pubmed: 28823003.

19. Jung J, Yim JH, Kwon YD, et al. A radiographic study of the position and prevalence of the maxillary arterial endosseous anastomosis using cone beam computed tomography. Int J Oral Maxillofac Implants. 2011; 26(6): 1273-1278, indexed in Pubmed: 22167433.

20. Kolli NK, Nirmala SV, Nuvvula S. The effectiveness of articaine and lidocaine single buccal infiltration versus conventional buccal and palatal injection using lidocaine during primary maxillary molar extraction: a randomized control trial. Anesth Essays Res. 2017; 11(1): 160-164, doi: 10.4103/02591162.186589, indexed in Pubmed: 28298777.

21. Liang $X$, Jacobs $R$, Martens $W$, et al. Macro- and micro-anatomical, histological and computed tomography scan characterization of the nasopalatine canal. J Clin Periodontol. 2009; 36(7): 598-603, doi: 10.1111/j.1600051X.2009.01429.x, indexed in Pubmed: 19538333.

22. Machado Vd, Chrcanovic BR, Felippe MB, et al. Assessment of accessory canals of the canalis sinuosus: a study of 1000 cone beam computed tomography examinations. Int J Oral Maxillofac Surg. 2016; 45(12): 1586-1591, doi: 10.1016/j. ijom.2016.09.007, indexed in Pubmed: 27720336.

23. Majid OW, Ahmed AM. The anesthetic efficacy of articaine and lidocaine in equivalent doses as buccal and non-palatal infiltration for maxillary molar extraction: a randomized, double-blinded, placebo-controlled clinical trial. J Oral Maxillofac Surg. 2018; 76(4): 737-743, doi: 10.1016/j. joms.2017.11.028, indexed in Pubmed: 29257943.

24. Manhães Júnior LR, Villaça-Carvalho MF, Moraes ME, et al. Location and classification of Canalis sinuosus for cone beam computed tomography: avoiding misdiagnosis. Braz Oral Res. 2016; 30(1): e49, doi: 10.1590/1807-3107BOR2016.vol30.0049, indexed in Pubmed: 27119586.

25. Mittal M, Sharma S, Kumar A, et al. Comparison of anesthetic efficacy of articaine and lidocaine during primary maxillary molar extractions in children. Pediatr Dent. 2015; 37(7): 520-524, indexed in Pubmed: 26883609. 
26. Neves FS, Crusoé-Souza M, Franco LC, et al. Canalis sinuosus: a rare anatomical variation. Surg Radiol Anat. 2012; 34(6): 563-566, doi: 10.1007/s00276-011-0907-6, indexed in Pubmed: 22134775.

27. Orhan K, Gorurgoz C, Akyol M, et al. An anatomical variant: evaluation of accessory canals of the canalis sinuosus using cone beam computed tomography. Folia Morphol. 2018; 77(3): 551-557, doi: 10.5603/FM.a2018.0003, indexed in Pubmed: 29345719.

28. Ortug A, Uzel M. Greater palatine foramen: assessment with palatal index, shape, number and gender. Folia Morphol. 2019; 78(2): 371-377, doi: 10.5603/FM.a2018.0088, indexed in Pubmed: 30234897.

29. Ozeç I, Taşdemir U, Gümüş $C$, et al. Is it possible to anesthetize palatal tissues with buccal $4 \%$ articaine injection? J Oral Maxillofac Surg. 2010; 68(5): 1032-1037, doi: 10.1016/j.joms.2009.12.023, indexed in Pubmed: 20223573.

30. Patel JR, Wuehrmann AH. A radiographic study of nutrient canals. Oral Surg Oral Med Oral Pathol. 1976; 42(5): 693-701, doi: 10.1016/0030-4220(76)90220-6, indexed in Pubmed: 1068424.

31. Piagkou M, Xanthos T, Anagnostopoulou S, et al. Anatomical variation and morphology in the position of the palatine foramina in adult human skulls from Greece. J Craniomaxillofac Surg. 2012; 40(7): e206-e210, doi: 10.1016/j. jcms.2011.10.011, indexed in Pubmed: 22055651.

32. Shelley AM, Rushton VE, Horner K. Canalis sinuosus mimicking a periapical inflammatory lesion. Br Dent J. 1999; 186(8): 378-379, doi: 10.1038/sj.bdj.4800116, indexed in Pubmed: 10365458.

33. Tavelli L, Barootchi S, Ravidà A, et al. What is the safety zone for palatal soft tissue graft harvesting based on the locations of the greater palatine artery and foramen? A systematic review. J Oral Maxillofac Surg. 2019; 77(2): 271.e1-271.e9, doi: 10.1016/j.joms.2018.10.002, indexed in Pubmed: 30395825.
34. Tomaszewska IM, Tomaszewski KA, Kmiotek EK, et al. Anatomical landmarks for the localization of the greater palatine foramen: a study of 1200 head CTs, 150 dry skulls, systematic review of literature and meta-analysis. J Anat. 2014; 225(4): 419-435, doi: 10.1111/joa.12221, indexed in Pubmed: 25131842.

35. Tomaszewska IM, Frączek P, Gomulska M, et al. Sex determination based on the analysis of a contemporary Polish population's palatine bones: a computed tomography study of 1,200 patients. Folia Morphol. 2014; 73(4): 462-468, doi: 10.5603/FM.2014.0069, indexed in Pubmed: 25448904.

36. Tomaszewska IM, Kmiotek EK, Pena IZ, et al. Computed tomography morphometric analysis of the greater palatine canal: a study of 1,500 head CT scans and a systematic review of literature. Anat Sci Int. 2015; 90(4): 287-297, doi: 10.1007/ s12565-014-0263-9, indexed in Pubmed: 25467526.

37. Tomaszewska IM, Zwinczewska H, Gładysz T, et al. Anatomy and clinical significance of the maxillary nerve: a literature review. Folia Morphol. 2015; 74(2): 150-156, doi: 10.5603/FM.2015.0025, indexed in Pubmed: 26050800.

38. Torres MG, de Faro Valverde L, Vidal MT, et al. Branch of the canalis sinuosus: a rare anatomical variation: a case report. Surg Radiol Anat. 2015; 37(7): 879-881, doi: 10.1007/ s00276-015-1432-9, indexed in Pubmed: 25616849.

39. von Arx T, Lozanoff S. Anterior superior alveolar nerve (ASAN). Swiss Dent J. 2015; 125(11): 1202-1209, indexed in Pubmed: 26631255.

40. von Arx T, Lozanoff S, Sendi P, et al. Assessment of bone channels other than the nasopalatine canal in the anterior maxilla using limited cone beam computed tomography. Surg Radiol Anat. 2013; 35(9): 783-790, doi: 10.1007/ s00276-013-1110-8, indexed in Pubmed: 23539212.

41. Wanzeler AM, Marinho CG, Alves Junior SM, et al. Anatomical study of the canalis sinuosus in 100 cone beam computed tomography examinations. Oral Maxillofac Surg. 2015; 19(1): 49-53, doi: 10.1007/s10006-014-04509, indexed in Pubmed: 24752931. 